\title{
Determination of the Antimicrobial Property of Oregano (Plectranthus amboinicus (Lour.) Spreng.) Crude Aqueous Leaf Extract against Throat Pathogens Using Broth and Checkerboard Dilution Methods
}

\author{
Sofia Isabel T. Manlubatan, MD, Kara Mae H. Matias, MD, Kenneth Roy P. Mendoza, MD, \\ Sheryll Anne R. Manalili, MD, Kris Conrad M. Mangunay, MD, Christine Mae G. Olivar, MD, \\ Johnnel G. Pahila, MD, Greco Mark B. Malijan, MD, Paulo Miguel G. Manzanilla, MD, \\ Marie Abigail M. Marin, MD, Ramon Joseph Y. Mata, MD, Abdel Hadi M. Mohammad Isa, MD, \\ Carla Maja Lizl A. Montaña, MD, Maika Kamille M. Mortell, MD, Mark Terence P. Mujer, MD, \\ Patricia A. Nacianceno, MD, Maria Regina Rocio S. Naval, MD, Joseph V. Oraño, MD, Gabriel M. Ozoa, MD, \\ Alfredo P. Pacheco, MD, Leonila E. Casanova, MD and Cleotilde H. How, MD \\ College of Medicine, Philippine General Hospital, University of the Philippines Manila
}

\begin{abstract}
Objective. This study aimed to determine the antimicrobial property of oregano (Plectranthus amboinicus) crude leaf extract against pathogens that infect the throat, specifically Streptococcus pyogenes and Candida albicans using the broth and checkerboard dilution methods.

Methods. This study employed an experimental study design using broth dilution method for the determination of the minimum inhibitory concentration (MIC), minimum bactericidal concentration (MBC) against Streptococcus pyogenes ATCC 19615, and minimum fungicidal concentration (MFC) against Candida albicans ATCC 14053 of P. amboinicus crude extract (PA extract). Checkerboard dilution method was then used for determination of the synergy between PA extract and the standard antimicrobials.
\end{abstract}

Results. In vitro growth inhibition of S. pyogenes (MIC $0.13 \mathrm{~g} / \mathrm{mL}$ ) and C. albicans (MIC $0.03 \mathrm{~g} / \mathrm{mL}$ ) was exhibited by the PA extract. The highest concentration of PA extract used in this study was not sufficient to demonstrate bactericidal and fungicidal activity (MBC $>0.25 \mathrm{~g} / \mathrm{mL}, \mathrm{MFC}>0.25 \mathrm{~g} / \mathrm{mL}$ ). Results of checkerboard dilution method revealed that PA extract when combined with either penicillin (for S. pyogenes) or nystatin (for C. albicans) demonstrated indifference.

Conclusion. The crude extract of Plectranthus amboinicus has the capability to inhibit the growth of both S. pyogenes and C. albicans. This demonstrates its potential use in the treatment of throat infections caused by these organisms.

Key Words: Plectranthus amboinicus, oregano, antimicrobial, throat infections, herbal medicine

\section{INTRODUCTION}

First place in the Pharmacology and Toxicology category of the $23^{\text {rd }}$ European Students' Conference held on September 2012, in Berlin, Germany.

Corresponding author: Sofia Isabel T. Manlubatan, MD

College of Medicine

Philippine General Hospital

University of the Philippines Manila

Email: sofia.manlubatan@gmail.com
Infections of the throat are usually caused by pathogens that infect the upper respiratory tract. The primary complaint of patients suffering from throat infections, both acute and chronic, is difficulty in swallowing and eating, and in worse cases, difficulty in talking and breathing. Certain organisms may also lead to severe systemic complications outside the upper respiratory tract such as in the case of group A beta-hemolytic streptococcus, Streptococcus pyogenes; and for others, may affect immunocompromised individuals as in the case of Candida albicans, which causes oral thrush among neonates. These infections are treated with antimicrobials. 
However, some people have developed hypersensitivity reactions against certain antimicrobials; and also for some, due to the irrational use of antibiotics, they have developed resistance to microorganisms despite use of these recommended antimicrobials. Therefore, it is important to look for alternative treatments to infections.

Many plants have been shown to have promising antimicrobial properties, and among these is Plectranthus amboinicus (PA), from the family commonly Lamiaceae, known as oregano or suganda. Its other scientific names are Coleus amboinicus and Coleus aromaticus. It is an erect, spreading, branched herb which can grow up to $50 \mathrm{~cm}$ tall and has fleshy stems up to $180 \mathrm{~cm}$ long. Its leaves are broadly ovate, fleshy, heart-shaped, and somewhat hairy with rounded, toothed margins. ${ }^{1}$ Its leaves, prepared as a decoction or juice, have been used as a remedy for throat infections, along with their culinary and economical uses., ${ }^{1,2}$ In the Philippines, apart from the traditional household preparation of the boiling the oregano leaves as cure for nasal congestion, cough, throat infections, headache, colic, dyspepsia, flatulence, rheumatism, myalgia, otalgia, and burns. ${ }^{1,3}$ In 2009, the Bureau of Agricultural Research of the Department of Agriculture funded a project to make a tea from oregano as well as soap. Production of oregano wine, oregano juice, and oregano vinegar are also in the works. ${ }^{2}$ Recently, a commercially prepared syrup has already been available in the market. Several previous studies appear to support these claims of tradition by demonstrating various therapeutic properties of this plant, such as antimicrobial, antiepileptic, and antioxidant. The antimicrobial effect of oregano has been demonstrated against Staphylococcus aureus and Escherichia coli, among others. ${ }^{3}$

This study aimed to determine the antimicrobial property of PA crude aqueous leaf extract against Streptococcus pyogenes and Candida albicans using the broth and checkerboard dilution methods. Specifically, this aimed to measure the minimum inhibitory concentration (MIC) against Streptococcus pyogenes and Candida albicans, the minimum bactericidal concentration (MBC) against Streptococcus pyogenes and minimum fungicidal concentration (MFC) against Candida albicans using broth dilution method; and to determine the synergism between PA crude aqueous leaf extract and the standard antimicrobial treatment using checkerboard dilution method.

Demonstration of the antimicrobial property of PA crude leaf extract against throat infections can help in the promotion of PA as a promising source of a novel drug compound that may potentially be just as effective, less toxic, and less expensive, than the current standard treatments against these infections. In addition, PA crude leaf extract can be used to find treatment for certain pathogenic organisms such as Streptococcus pyogenes and Candida albicans since these are very much susceptible to developing resistance against standard treatments. This study can also determine whether PA crude leaf extract can be used in combination with the standard treatment to improve the effect of these standard antimicrobials. This can also be used as a basis for further exploring the various compounds present. Also, since this study will make use of PA in its crude aqueous form and involved only basic processing procedures, it can demonstrate whether the one used in the local setting, most likely used as a home remedy, has any positive effects in terms of treating infections caused by these organisms.

\section{METHODOLOGY}

\section{Study Design and Population}

This study employed an experimental study design using the broth dilution method for the determination of the MIC of Plectranthus amboinicus crude aqueous leaf extract against Streptococcus pyogenes ATCC 19615 and Candida albicans ATCC 14053, MBC against $S$. pyogenes, and MFC against C. albicans. This study was reviewed by the Institutional Biosafety and Biosecurity Committee of the University of the Philippines Manila.

\section{Materials and Methods}

\section{Plant Material}

Plectranthus amboinicus was procured from Institute of Plant Breeding in the University of the Philippines Los Baños, Laguna during the month of October. It was then verified by a taxonomist from the National Museum. The leaves of the plant were separated from the stalk, rinsed with tap water followed by distilled water, air dried at room temperature, oven dried at $40^{\circ} \mathrm{C}$, and macerated. The leaves were extracted using distilled water for 24 hours. The PA extract was filtered, and was then sent to the Tissue Bank of the Department of Orthopedics, Philippine General Hospital for lyophilization.

\section{Pre-testing}

A pre-test was done to determine the efficacy of the antibiotics to be used, the ability of the media to grow the organisms, and the $\mathrm{pH}$ of the $\mathrm{PA}$ crude aqueous extract.

\section{Antimicrobial Susceptibility Testing using the Broth Dilution Method}

Broth dilution was performed using two-fold dilution. Each set-up was done in triplicates.

\section{Preparation of Control and Treatment Groups}

The following controls and treatments were prepared: antibiotic only, PA crude extract only, media only, antibiotic + organism (positive control), PA crude extract + organism (treatment), media + organism (negative/growth control). The first three control groups were used as the respective comparators of test tubes inoculated with the organism. The concentration of the PA crude extract ranges from $1 \mathrm{mg} / \mathrm{mL}$ to $500 \mathrm{mg} / \mathrm{mL}$, which was extrapolated from toxicity studies 
done for PA aqueous crude extract. All reagents, media, and inoculums used were procured through the help of the Department of Microbiology, College of Public Health and Department of Pharmacology and Toxicology, College of Medicine, University of the Philippines Manila.

\section{Streptococcus pyogenes}

This procedure is based on the standards set by the Clinical and Laboratory Standards Institute (CLSI). ${ }^{4}$ Mueller-Hinton broth is the medium of choice in investigations involving commonly-isolated, rapidly-growing aerobic or facultative organisms, Streptococcus spp. being some of them. The use of this medium allows for good batch to batch reproducibility and produces satisfactory growth of most pathogens. Supplementation must be done to the broth depending on the desired inoculate to facilitate growth. For Streptococcus spp., the addition of blood is recommended. Monitoring of the broth must be done periodically, particularly its $\mathrm{pH}$, which must be maintained between 7.27.4 at room temperature $\left(25^{\circ} \mathrm{C}\right)$.

Dilutions of the chosen antimicrobial agents are done volumetrically, with a minimum final volume of $1 \mathrm{ml}$ in each test tube. These dilutions are usually prepared double the desired concentration, as addition of an equal volume of inoculum will result in a 1:2 concentration of the drugs. Incubation must be done in ambient air at $35 \pm 2{ }^{\circ} \mathrm{C}$ for $20-24$ hours before reading the MICs. The MIC range of penicillin for $S$. pyogenes is $\leq 0.25 \mu \mathrm{g} / \mathrm{ml}$.

The positive control for $S$. pyogenes contained MuellerHinton broth (MHB) and penicillin $\mathrm{G}$ sodium. The negative control contained MHB only. The treatment group contained PA crude extract in addition to the MHB.

Table 1. Composition of the control and treatment groups for S. pyogenes

\begin{tabular}{ll}
\multicolumn{1}{c}{ Rack } & \multicolumn{1}{c}{ Contents of first tube } \\
Positive Control & MH broth $(1 \mathrm{~mL})+$ penicillin $(1 \mathrm{~mL}, 1 \mu \mathrm{g} / \mathrm{mL})$ \\
Negative Control & $\mathrm{MH}$ broth $(2 \mathrm{~mL})$ \\
Treatment & MH broth $(1 \mathrm{~mL})+$ PA crude extract \\
& $(1 \mathrm{~mL}, 500 \mathrm{mg} / \mathrm{mL})$
\end{tabular}

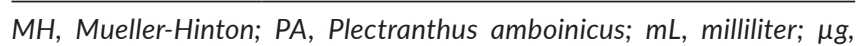
microgram; $\mathrm{mg}$, milligram

\section{Candida albicans}

The Clinical and Laboratory Standards Institute also set a protocol for testing fungi..$^{5}$ Usually, a synthetic medium is recommended for susceptibility tests, with a $\mathrm{pH}$ of $7.0 \pm 0.1$ at $25^{\circ} \mathrm{C}$. Test tubes $(12 \times 75 \mathrm{~mm})$ are prepared, including a growth control tube containing only the medium for each organism tested. Antifungal agents are prepared volumetrically. For non-water-soluble agents, DMSO is a common alternative.

Organisms are cultured in sterile vials onto Sabouraud dextrose agar or potato dextrose agar. Incubation temperature must be maintained at $35^{\circ} \mathrm{C}$ throughout. From this, inoculate is prepared by picking from 24-hour cultures of the Candida followed by suspension in sterile saline. Antifungal agents in desired concentrations are placed in test tubes. Ideally, inoculum must be introduced within 15 minutes of preparation. The tubes are then incubated in ambient air without agitation at $35^{\circ} \mathrm{C}$ for $46-50$ hours. Standards for the MIC range of nystatin against C. albicans have not yet been established.

The positive control for C. albicans contained Roswell Park Memorial Institute (RPMI) medium with 0.165 molar 3-( $N$-morpholino)propanesulfonic acid (MOPS) buffer and $2 \%$ sucrose added with nystatin. The negative control contained RPMI with 0.165 M MOPS buffer and $2 \%$ sucrose only. The treatment group contained PA crude extract in addition to the RPMI with $0.165 \mathrm{M}$ MOPS buffer and $2 \%$ sucrose.

Table 2. Composition of the control and treatment groups for C. albicans

\section{Rack Contents of first tube}

Positive Control RPMI with 0.165 M MOPS buffer and $2 \%$ sucrose $(1 \mathrm{~mL})+$ nystatin $(1 \mathrm{~mL}, 5 \mu \mathrm{g} / \mathrm{mL})$

Negative Control RPMI with 0.165 M MOPS buffer and 2\% sucrose $(2 \mathrm{~mL})$

Treatment $\quad$ RPMI with $0.165 \mathrm{M}$ MOPS buffer and $2 \%$ sucrose $(1 \mathrm{~mL})+$ PA crude extract $(1 \mathrm{~mL}, 500 \mathrm{mg} / \mathrm{mL})$

RPMI, Roswell Park Memorial Institute medium; MOPS, 3-(N-morpholino) propanesulfonic acid; PA, Plectranthus amboinicus; $M$, molar; $\mathrm{mL}$, milliliter; $\mu \mathrm{g}$, microgram; $\mathrm{mg}$, milligram

\section{Preparation of Inoculums}

$S$. pyogenes, incubated for 24 hours in $\mathrm{MH}$ broth was adjusted to $0.5 \mathrm{McFarland}$ Standard. This gives approximately $10^{6} \mathrm{cfu} / \mathrm{mL}$. C. albicans, on the other hand, incubated for 24 hours in RPMI with 0.165 M MOPS buffer and $2 \%$ sucrose was adjusted to $1.0 \mathrm{McF}$ arland Standard, giving approximately $5 \times 10^{5} \mathrm{cfu} / \mathrm{mL}$.

\section{Determination of Minimum Inhibitory Concentration}

One milliliter of MHB (for $S$. pyogenes) or RPMI with $0.165 \mathrm{M}$ MOPS buffer and $2 \%$ sucrose (for C. albicans) was placed in all the test tubes. The positive control containing $1 \mathrm{~mL}$ of $1.0 \mu \mathrm{g} / \mathrm{mL}$ penicillin (for $S$. pyogenes) or $1 \mathrm{~mL}$ of $5.0 \mu \mathrm{g} / \mathrm{mL}$ nystatin (for C. albicans) was added to the first test tube. Two-fold serial dilution was done for the next nine test tubes prior to the inoculation of the organism.

The first test tube in the treatment group contained $1 \mathrm{~mL}$ of $500 \mathrm{mg} / \mathrm{mL}$ PA crude extract, also serially diluted prior to inoculation of the organism. All test tubes were incubated for 18 to 24 hours at $37^{\circ} \mathrm{C}$. The lowest concentration of penicillin, nystatin, and PA crude extract without growth was reported as the MIC based on visual comparison with the negative control group. The MICs obtained were used as the basis for determining the synergism between PA crude extract and the standard antimicrobials. 
Determination of the Minimum Bactericidal Concentration of Streptococcus pyogenes and Minimum Fungicidal Concentration of Candida albicans

All test tubes were spread plated in Blood Agar for $S$. pyogenes or Saboraud's Dextrose Agar for C. albicans. After 24 hours of incubation in $37^{\circ} \mathrm{C}$, the $\mathrm{MBC}$ of $\mathrm{PA}$ crude extract and penicillin against $S$. pyogenes and MFC of PA crude extract and nystatin against $C$. albicans were determined as the lowest concentration at which there is no growth or complete inhibition of colony formation of the organism.

\section{Synergism of Plectranthus amboinicus Extract and the Standard Antimicrobials}

Checkerboard dilution method was used to determine the synergism of PA crude extract and the standard antimicrobials. This method, though not yet standardized as of present time, is a two-dimensional, two-agent dilution method that aims to test the interaction of specific concentrations of antimicrobials in combination at a fixed time. ${ }^{6}$ Results are interpreted as synergistic, indifferent, or antagonistic depending on whether the antimicrobial activity in combination is greater than, equivalent to, or less than the activities of the individual antimicrobials, respectively. This is determined via computation of the fractional inhibitory concentration index ( $\Sigma$ FIC), which is the sum of the FICs of each antimicrobial. FIC is defined as the MIC of two antimicrobials when used in combination divided by the MIC of each antimicrobial when used alone. ${ }^{7}$ The following is the interpretation of the computed $\Sigma \mathrm{FIC}$ :

\begin{tabular}{cc}
\hline FIC & Interpretation \\
$\leq 0.5$ & Synergistic \\
$>0.5$ and $\leq 4$ & Indifferent \\
$>4.0$ & Antagonistic \\
\hline
\end{tabular}

Based on the results of the MIC, the following concentrations of both PA crude extract and standard antimicrobials for each organism were prepared: $0.5 \mathrm{MIC}, 1$ MIC, 2 MIC. Each concentration of PA crude extract was added to each concentration of the standard antimicrobial, giving a total of nine combinations per set-up. After 18 to 24 hours of incubation at $37^{\circ} \mathrm{C}$, the fractional inhibitory concentration indices $(\Sigma \mathrm{FIC})$ were computed.

\section{RESULTS}

\section{Pre-test}

Characterization of the test substance was done during the pre-testing. The minimum inhibitory concentration was not determined due to the color of the crude extract, hence agar dilution method was employed for selected tubes with higher concentrations. The minimum bactericidal concentration of PA crude extract against Streptococcus pyogenes was at $30 \mathrm{mg} / \mathrm{mL}$, while the minimum fungicidal concentration against Candida albicans was at $130 \mathrm{mg} / \mathrm{mL}$. These results were used as the basis of the concentration of the PA crude extract for the actual experiment.

\section{Plectranthus amboinicus}

From the raw plant material, the yield of the lyophilized crude extract is $0.3 \%$. The lyophilized extract is opaque, brown to dark brown crystals, with a burnt mint odor and bitter taste, and soluble in water and plain normal saline solution (NSS). The $\mathrm{pH}$ of $500 \mathrm{mg}$ PA extract dissolved in 1 $\mathrm{mL}$ plain NSS is 7.08 .

\section{Antimicrobial Susceptibility Testing using Broth Dilution Method}

The minimum inhibitory concentration of penicillin on $S$. pyogenes using the broth dilution method was between $0.03-0.06 \mu \mathrm{g} / \mathrm{mL}$, which was also the bactericidal concentration of this drug on testing. PA crude extract, on the other hand, inhibited the growth of $S$. pyogenes at 130 $\mathrm{mg} / \mathrm{mL}$. This is in contrast with the higher bactericidal concentration which was more than $250 \mathrm{mg} / \mathrm{mL}$. For C. albicans, nystatin was inhibitory at a concentration of $0.04 \mu \mathrm{g} / \mathrm{mL}$, and fungicidal at a higher concentration of $0.63 \mu \mathrm{g} / \mathrm{mL}$. The PA crude extract exhibited inhibitory activity at $30 \mathrm{mg} / \mathrm{mL}$ and was fungicidal at concentrations higher than $250 \mathrm{mg} / \mathrm{mL}$.

Table 3. Minimum inhibitory, bactericidal and fungicidal concentrations of various antimicrobials against Streptococcus pyogenes and Candida albicans

\begin{tabular}{cccc} 
Organism & $\begin{array}{c}\text { Anti- } \\
\text { microbial }\end{array}$ & MIC & $\begin{array}{c}\text { MBC (for S. pyogenes) } \\
\text { or MFC (for C. albicans) }\end{array}$ \\
\hline \multirow{2}{*}{\begin{tabular}{c} 
Streptococcus $\begin{array}{c}\text { pyogenes } \\
\text { pyonicillin }\end{array}$ \\
\cline { 2 - 4 } ATCC 19615
\end{tabular}} & $\begin{array}{c}\text { PA crude } \\
\text { extract }\end{array}$ & $130 \mathrm{mg} / \mathrm{mL}$ & $>250 \mathrm{mg} / \mathrm{mL}$ \\
\hline $\begin{array}{c}\text { Candida } \\
\text { albicans }\end{array}$ & Nystatin & $0.04 \mu \mathrm{g} / \mathrm{mL}$ & $0.63 \mu \mathrm{g} / \mathrm{mL}$ \\
\cline { 2 - 4 } ATCC 14053 & $\begin{array}{c}\text { PA crude } \\
\text { extract }\end{array}$ & $30 \mathrm{mg} / \mathrm{mL}$ & $>250 \mathrm{mg} / \mathrm{mL}$ \\
\hline
\end{tabular}

MIC, minimum inhibitory concentration; MBC, minimum bactericidal concentration; MFC, minimum fungicidal concentration

\section{Synergism Testing using Checkerboard Dilution Method}

Fractional inhibitory concentrations (FIC) of each component sample were calculated by dividing the MIC of one component in combination by its MIC when used alone. ${ }^{6}$

The fractional inhibitory concentration index $(\Sigma F I C)$ was calculated by summating the FIC of both the antimicrobial agent and PA crude extract.

$$
\mathrm{FIC}=\frac{\text { MIC in combination }}{\text { MIC alone }}
$$


Table 4. Minimum inhibitory concentration (MIC), fractional inhibitory concentration (FIC) and FIC index ( $\mathrm{FIC}$ ) for synergism testing of S. pyogenes using checkerboard dilution method

\begin{tabular}{|c|c|c|c|c|c|c|}
\hline \multicolumn{2}{|c|}{ Combination Tubes } & \multirow{2}{*}{ Growth } & \multirow{2}{*}{ FIC Penicillin } & \multirow{2}{*}{$\begin{array}{c}\text { FIC PA } \\
\text { crude extract }\end{array}$} & \multirow{2}{*}{$\Sigma F I C$} & \multirow{2}{*}{ Interpretatior } \\
\hline Penicillin concentration $(\mu \mathrm{g} / \mathrm{mL})$ & PA extract concentration $(\mathrm{mg} / \mathrm{mL})$ & & & & & \\
\hline 0.12 & 250 & + & Growth & Growth & Growth & \\
\hline 0.12 & 130 & + & Growth & Growth & Growth & \\
\hline 0.12 & 60 & + & Growth & Growth & Growth & \\
\hline 0.06 & 250 & - & 1.0 & 2.0 & 3.0 & Indifferent \\
\hline 0.06 & 130 & - & 1.0 & 1.0 & 2.0 & Indifferent \\
\hline 0.06 & 60 & - & 1.0 & 0.5 & 1.5 & Indifferent \\
\hline 0.03 & 250 & + & Growth & Growth & Growth & \\
\hline 0.03 & 130 & - & 0.5 & 1.0 & 1.5 & Indifferent \\
\hline 0.03 & 60 & - & 0.5 & 0.5 & 1.0 & Indifferent \\
\hline
\end{tabular}

PA, Plectranthus amboinicus; MIC, minimum inhibitory concentration; FIC, fractional inhibitory concentration; $\Sigma$ FIC, FIC index

Table 5. Minimum bactericidal concentration (MBC), fractional bactericidal concentration (FBC) and $F B C$ index $(\Sigma F B C)$ for synergism testing of $S$. pyogenes using checkerboard dilution method

\begin{tabular}{|c|c|c|c|c|c|c|}
\hline \multicolumn{2}{|c|}{ Combination Tubes } & \multirow{2}{*}{ Growth } & \multirow{2}{*}{ FIC Penicillin } & \multirow{2}{*}{$\begin{array}{c}\text { FIC PA } \\
\text { crude extract }\end{array}$} & \multirow{2}{*}{$\Sigma \mathrm{FIC}$} & \multirow{2}{*}{ Interpretation } \\
\hline Penicillin concentration $(\mu \mathrm{g} / \mathrm{mL})$ & PA extract concentration $(\mathrm{mg} / \mathrm{mL})$ & & & & & \\
\hline 0.12 & 250 & - & 2.0 & 2.0 & 4.0 & Indifferent \\
\hline 0.12 & 130 & - & 2.0 & 1.0 & 3.0 & Indifferent \\
\hline 0.12 & 60 & - & 2.0 & 0.5 & 2.5 & Indifferent \\
\hline 0.06 & 250 & - & 1.0 & 2.0 & 3.0 & Indifferent \\
\hline 0.06 & 130 & - & 1.0 & 1.0 & 2.0 & Indifferent \\
\hline 0.06 & 60 & - & 1.0 & 0.5 & 1.5 & Indifferent \\
\hline 0.03 & 250 & - & 0.5 & 2.0 & 2.5 & Indifferent \\
\hline 0.03 & 130 & - & 0.5 & 1.0 & 1.5 & Indifferent \\
\hline 0.03 & 60 & - & 0.5 & 0.5 & 1.0 & Indifferent \\
\hline
\end{tabular}

PA, Plectranthus amboinicus; $M B C$, minimum bactericidal concentration; FBC, fractional bactericidal concentration; $\Sigma F B C, F B C$ index

\section{Streptococcus pyogenes}

Tables 4 and 5 summarize the results for the synergism testing of penicillin and PA crude extract against $S$. pyogenes. All combinations with the MIC of penicillin $(0.06 \mu \mathrm{g} /$ $\mathrm{mL}$ ) regardless of the $\mathrm{PA}$ crude extract concentration, and those using half the MIC of penicillin except one, resulted to indifference. Growth was observed with higher concentrations of penicillin. However, all combinations were observed to be bactericidal upon plating, though all of them still resulted to indifference.

\section{Candida albicans}

Only those with higher concentrations of either the antifungal or PA crude extract inhibited growth in culture. $\Sigma F I C$ of these combinations resulted to neither antagonism nor synergism. Only those with the highest concentration of PA crude extract $(60 \mathrm{mg} / \mathrm{mL})$ were able to kill the organism.

\section{DISCUSSION}

Present-day research has been geared towards finding new drugs with higher efficacy and fewer side effects against a wider variety of pathogens which commonly infect the human body. While these new drugs are still on the process of being discovered, the use of combinations of antimicrobial drugs is aimed at addressing the continuous emergence of resistant strains among common pathogens. With this, the age-long use of alternative naturally-occurring substances is still widely known and practiced. Determination of the antimicrobial property of oregano (Plectranthus amboinicus) crude leaf aqueous extract against throat pathogens using broth and checkerboard dilution methods is presented in this paper.

\section{Infections of the Throat}

Several organisms may cause throat infections. Some of these are Streptococcus pyogenes and Candida albicans.

\section{Streptococcus pyogenes}

Streptococcus pyogenes is a species of Gram-positive cocci, identifiable in culture by a beta-hemolytic colony pattern on a blood agar plate. The colonies appear white, with a clear zone forming around colonies that indicate where hemolysins from the bacteria have destroyed red blood cells. ${ }^{8}$ 
Table 6. Minimum inhibitory concentration (MIC), fractional inhibitory concentration (FIC) and FIC index ( $\mathrm{FIC}$ ) for synergism testing of C. albicans using checkerboard dilution method

\begin{tabular}{|c|c|c|c|c|c|c|}
\hline \multicolumn{2}{|c|}{ Combination Tubes } & \multirow{2}{*}{ Growth } & \multirow{2}{*}{ FIC Nystatin } & \multirow{2}{*}{$\begin{array}{c}\text { FIC PA } \\
\text { crude extract }\end{array}$} & \multirow{2}{*}{$\Sigma F I C$} & \multirow{2}{*}{ Interpretation } \\
\hline Nystatin concentration $(\mu \mathrm{g} / \mathrm{mL})$ & PA extract concentration $(\mathrm{mg} / \mathrm{mL})$ & & & & & \\
\hline 0.08 & 60 & - & 2.0 & 2.0 & 4.0 & Indifferent \\
\hline 0.08 & 30 & - & 2.0 & 1.0 & 3.0 & Indifferent \\
\hline 0.08 & 15 & - & 2.0 & 0.5 & 2.5 & Indifferent \\
\hline 0.04 & 60 & - & 1.0 & 2.0 & 3.0 & Indifferent \\
\hline 0.04 & 30 & + & Growth & Growth & Growth & \\
\hline 0.04 & 15 & + & Growth & Growth & Growth & \\
\hline 0.02 & 60 & - & 0.5 & 2.0 & 2.5 & Indifferent \\
\hline 0.02 & 30 & + & Growth & Growth & Growth & \\
\hline 0.02 & 15 & + & Growth & Growth & Growth & \\
\hline
\end{tabular}

PA, Plectranthus amboinicus; MIC, minimum inhibitory concentration; FIC, fractional inhibitory concentration; $\Sigma$ FIC, FIC index

Table 7. Minimum fungicidal concentration (MFC), fractional fungicidal concentration (FFC) and FFC index ( $\Sigma F F C$ ) for synergism testing of $\mathrm{C}$. albicans using checkerboard dilution method

\begin{tabular}{|c|c|c|c|c|c|c|}
\hline \multicolumn{2}{|c|}{ Combination Tubes } & \multirow{2}{*}{ Growth } & \multirow{2}{*}{ FIC Nystatin } & \multirow{2}{*}{$\begin{array}{c}\text { FIC PA } \\
\text { crude extract }\end{array}$} & \multirow{2}{*}{$\Sigma F I C$} & \multirow{2}{*}{ Interpretation } \\
\hline Nystatin concentration $(\mu \mathrm{g} / \mathrm{mL})$ & PA extract concentration $(\mathrm{mg} / \mathrm{mL})$ & & & & & \\
\hline 0.08 & 60 & - & 2.0 & 2.0 & 4.0 & Indifferent \\
\hline 0.08 & 30 & + & Growth & Growth & Growth & \\
\hline 0.08 & 15 & + & Growth & Growth & Growth & \\
\hline 0.04 & 60 & + & Growth & Growth & Growth & \\
\hline 0.04 & 30 & + & Growth & Growth & Growth & \\
\hline 0.04 & 15 & + & Growth & Growth & Growth & \\
\hline 0.02 & 60 & - & 0.5 & 2.0 & 2.5 & Indifferent \\
\hline 0.02 & 30 & + & Growth & Growth & Growth & \\
\hline 0.02 & 15 & + & Growth & Growth & Growth & \\
\hline
\end{tabular}

PA, Plectranthus amboinicus; MFC, minimum fungicidal concentration; FFC, fractional fungicidal concentration; $\Sigma F B C, F B C$ index

Microscopically, the bacterial cocci have a diameter of $1 \mu \mathrm{m}$ and form chains. ${ }^{9}$

S. pyogenes infects hosts by targeting host molecules present on mucosal surfaces or skin..$^{10}$ The bacteria possess at least nine fibronectin-binding adhesins which are important factors in group A streptococcal virulence. The hyaluronic capsule of $S$. pyogenes binds to CD44 molecules found on the surface of human keratinocytes, the principal cell type in skin and the pharyngeal epithelium..$^{10}$ Other important toxins and enzymes that contribute to the pathogenicity of $S$. pyogenes include, but are not limited to pyrogenic streptococcal exotoxins, streptokinase, hyaluronidase, and streptolysin $\mathrm{O}$ and S. ${ }^{9}$ The incubation period for $S$. pyogenes lasts between 2 and 7 days, followed by a fever that would last 3-5 days. ${ }^{8}$

The beta-hemolytic group A streptococci (GAS) most often cause a mild throat or skin infection, although in some cases it becomes increasingly toxic and fatal as rheumatic fever, rheumatic heart disease, acute glomerulonephritis, and possible pediatric autoimmune neuropsychiatric disorder associated with streptococci (PANDAS). ${ }^{11,12}$ In persons with a high-risk MHC II allotype, there are rare cases of severe septic infection and necrotizing fasciitis. ${ }^{8,11}$
According to Pichichero, GAS pathogens cause pharyngitis up to a peak incidence of 28 to $40 \%$ in children and 5 to $9 \%$ in adults, but infection frequency varies according to geographical area, season, and age. ${ }^{9,12}$ Changes in infection patterns are being monitored by various research efforts across different continents to track currently evolving $S$. pyogenes serotypes and resistances. ${ }^{13-16}$ Humans remain to be the only pathogen reservoir for group A betahemolytic streptococci, with $S$. pyogenes being able to survive intracellularly for a time, explaining recurrences that occur after adequate antibiotic treatment. ${ }^{8,9,17}$

Treatment of group A beta-hemolytic streptococcal pharyngitis is done mainly by the administration of oral penicillin for 10 days. ${ }^{18}$ It is the drug of choice because of its narrow spectrum, safety and low cost. New studies suggest that amoxicillin taken once a day for 10 days is as effective as multiple daily doses of penicillin $V \cdot{ }^{18,19} \mathrm{~S}$. pyogenes is also susceptible to azithromycin, erythromycin, roxithromycin and clarithromycin in vitro, and roxithromycin $150 \mathrm{mg}$ producing less antibiotic-related side effects than with erythromycin. ${ }^{20,21}$ However, the use of macrolides in treatment is more expensive than the use of penicillin. ${ }^{21}$ 
In addition, extensive use of macrolides develops streptococcal resistance to these, which is not the case with the use of penicillin. ${ }^{18}$

\section{Candida albicans}

Candida albicans is diploid fungus that displays abilities to exist as yeast and filamentous cells and causes the most number of oral and genital infections in humans. ${ }^{22}$ Fungemia in the background of invasive candidiasis secondary to immunocompromised states such as cancer chemotherapy, organ and/or bone marrow transplant, post-surgery and full-blown AIDS has been a significant cause of morbidity and mortality. Nosocomial infection due to C. albicans is a particular health concern in the hospitals. Risk factors in developing funginemia include use of broad-spectrum antibiotics, candidiasis, dialysis, diabetes, use of yeast probiotics, presence of mercury in amalgams, multiple abdominal surgeries, use of steroids and burns, among others.

C. albicans is also the most common organism that can cause oropharyngeal candidiasis (thrush), which is common among neonates and immunocompromised individuals. Patients often presents with sore throat, burning tongue, and friable white or gray plaques on the gingival, tongue, and oral mucosa. ${ }^{23}$

A study conducted by the Department of Health Research Institute for Tropical Medicine to determine the prevalence of fungal infections by analysis of scrapings from skin, oral mucosa, tissue biopsies and nails showed Candida spp. as the most common isolate, with C. albicans occurring most frequently, almost four times more frequently than the C. tropicans that followed it..$^{22}$ In another study done at the Santo Tomas University Hospital Private Division, Candida spp. ranked third in isolates responsible for the nosocomial infections with C. albicans again most commonly identified, particularly in the mouth and urinary tract, as well as in patients with blood dyscrasias. ${ }^{24}$ Recently, it has garnered more attention as the prevalence of immunocompromised states continues to rise, particularly, infections with HIV/ AIDS, as oropharyngeal candidiasis is an extremely common finding in such patients. ${ }^{25}$

Changes in the human oral flora local microenvironment or, more importantly, host defenses, trigger infection. ${ }^{26}$ Traditionally, CD4+ T-lymphocyte counts less than 200 cells/ $\mu 1$ have been associated with increased risk for developing the infection. ${ }^{25}$ This may present as white curdlike plaques on the buccal mucosa, erythematous patches on the palates or dorsum of the tongue, as firmly adherent white patches, or as fissures in the corners of the mouth, depending on the type. ${ }^{27}$ C. albicans possesses many virulence factors to affect this, including their ability to adhere to both endothelial and epithelial cells, develop pseudohyphae or hyphae, as well as their secretion of proteinases and other lytic enzymes. Another significant factor to be considered is their capacity for phenotypic switching to be able to enter a cell to infect it. ${ }^{25}$
Regardless, affliction with oropharyngeal candidiasis is a valid concern as, when complicated with esophageal candidiasis, it may have effects on food consumption leading to weight loss, and deprivation of nourishment may be hazardous. ${ }^{28}$ In addition to physical discomfort in the oral cavity, the lesions are also associated with altered taste sensation and dysphagia, furthering the state of poor nutrition. ${ }^{26}$

Thrush is usually treated with nystatin, clotrimazole, or fluconazole. ${ }^{23}$ However, some studies have shown that C. albicans has now developed resistance. This resistance to the antifungal agent fluconazole is often caused by the over-expression of genes that encode multidrug efflux pumps (CDR1, CDR2, or MDR1). ${ }^{29}$

\section{Plectranthus amboinicus: Toxicity Studies}

A study on the acute toxicity of $P$. amboinicus methanolic extract in albino mice revealed that there was no mortality observed up to the maximum dose level of $2000 \mathrm{mg} / \mathrm{kg}$ for 7 days of oral administration, which is the recommended single high dose by Organization for Economic Cooperation and Development (OECD) guidelines for testing acute toxicity. No changes attributable to treatment were found in body weight, respiration rate, and heart rate. ${ }^{30}$ The same study also investigated sub-acute toxicity and found that hematological (e.g., platelet count, mean corpuscular volume, etc.) and biochemical parameters (e.g., transaminase, serum total albumin, etc.) were within the normal range after ingestion of 200 and $400 \mathrm{mg} / \mathrm{kg}$ doses of the extract for 28 days. In addition, no morphological disturbances were found upon histopathological examination of vital organs. ${ }^{30}$

The toxicity results of the previous study also parallel that of Tillian et al. and Patel. Tillain et al. demonstrated the absence of hematological, blood chemical, histological, and behavioral indicators of toxicity of a subchronic ( 90 days) administration of 500 and $50 \mathrm{mg}$ aqueous extract of the aerial parts of $P$. amboinicus. ${ }^{31}$ Patel also demonstrated absence of acute toxicity in albino rats after administration of ether, chloroform, ethanolic, and aqueous extracts of $P$. amboinicus extract for 48 hours, with an $\mathrm{LD}_{50}$ estimated to be $>5000 \mathrm{mg} / \mathrm{kg} .{ }^{31}$ It was recommended that the margin of safety dosage to be one-tenth of the $\mathrm{LD}_{50}, 500 \mathrm{mg} / \mathrm{kg} .{ }^{31} \mathrm{In}$ this study, we used aqueous PA crude extract ranging from $1 \mathrm{mg} / \mathrm{mL}$ to $500 \mathrm{mg} / \mathrm{mL}$, which is within the safety dosage identified from these studies.

\section{Plectranthus amboinicus: Recent Antimicrobial Studies}

Research into the antimicrobial properties of $P$. amboinicus has been extensive. Its fresh leaves are effective against the microbes that cause most reproductive tract infections in women such as Candida krusei, Candida albicans, Proteus mirabilis, and Escherichia coli; however, it is not as effective against Staphylococcus aureus, Enterococcus faecalis, Klebsiella pneumoniae, and Neisseria gonorrheae. ${ }^{32}$ 
The ethanol extract of the leaves of $P$. amboinicus were proven to be effective in inhibiting some Gram-positive and Gram-negative bacteria including Escherichia coli, and even methicillin-resistant Staphylococcus aureus (MRSA). ${ }^{33-35}$ However, it is not effective against Pseudomonas aeruginosa. ${ }^{33}$ Methanol extract also exhibited significant bactericidal activity against Bacillus subtilis. ${ }^{36}$

Its essential oils have been proven effective against Bacillus firmus, Bacillus subtilis Staphylococcus aureus, Salmonella typhi, Klebsiella oxytoca, Proteus mirabilis, Aspergillus flavus, Aspergillus niger, Aspergillus ochraceus, Aspergillus oryzae, Candida albicans, Fusarium sp., Penicillium sp., and Sacharomyces cerevisiae. ${ }^{37-39}$ However, the essential oils were not proven to have antibacterial effect against Escherichia coli. ${ }^{40}$

No study to date had been able to show how the fresh or crude leaf extract of the plant can affect the growth of Streptococcus pyogenes. In addition, this study was able to validate results of other studies that demonstrated the antifungal effect of $P$. amboinicus against Candida albicans but this time, using crude aqueous leaf extract.

\section{Antimicrobial Susceptibility Testing using the Broth Dilution Method}

Results showed that the aqueous PA crude extract was effective in inhibiting growth of Streptococcus pyogenes, with the minimum inhibitory concentration (MIC) at $130 \mathrm{mg} /$ $\mathrm{mL}$, and also Candida albicans with the MIC at $30 \mathrm{mg} / \mathrm{mL}$. A previous study on the phytochemical analysis of PA crude water extracts revealed the following components: flavonoid, proteins, amino acids, tannins, phenolic compounds, terpenoids, carbohydrates, glycosides, and alkaloids. ${ }^{41}$ Among these, its antibacterial and antifungal properties may be attributed to terpenoids, aldehydes, and phenols particularly carvacrol, thymol, and eugenol. ${ }^{42-45}$ Several previous studies showed that terpenic and cinnamic derivatives of PA cause damage to microbes by destroying cell membrane and causing cell lysis. ${ }^{46,47}$ The results were similar with other studies which used the ethanol extract of PA on Gram-positive and Gram-negative bacteria such as Escherichia coli and methicillin-resistant Staphylococcus aureus. ${ }^{48,49}$ Other studies also showed that the essential oils of PA, rather than the fresh crude extract, are effective against $C$. albicans. ${ }^{50-52}$ However, Pritima and Pandian were able to demonstrate PA's activity against $C$. albicans using fresh leaves as antibiotic discs. ${ }^{53}$ Furthermore, these components were hypothesized to have synergistic effects in producing antibacterial and antifungal properties of PA extract. The rationale for using the aqueous leaf extract of oregano in this study is that it reflects how it is being prepared and used in the community.

The PA crude extract concentrations tested for this study did not exhibit bactericidal and fungicidal properties against $S$. pyogenes and C. albicans, respectively. Growth of these organisms upon inoculation was observed even after the highest concentration of PA extract $(250 \mathrm{mg} / \mathrm{mL})$ was added. Tschesche observed the same findings using another plant and suggested that in order to observe the bactericidal and fungicidal properties, a higher concentration should be used in the study. ${ }^{54}$ However, it is important to note that during the exploratory phase or pre-test of this study, bactericidal and fungicidal concentrations were observed at $30 \mathrm{mg} / \mathrm{mL}$ and $130 \mathrm{mg} / \mathrm{mL}$, respectively. It is probable that in higher concentrations, PA crude extract is also capable of acting as a bactericidal against $S$. pyogenes and fungicidal against $C$. albicans. These differences in the result of the pre-test and the actual test may be attributed to the effects of seasonal variation in the active compounds present in the plant. ${ }^{51}$ Johnson et al. studied the effect of seasonal variation in the volatile oil content and composition of individuals of Origanum vulgare, a plant species related to PA. It was observed that $p$-cymene, carvacrol, and thymol, the same active components found in PA, are all affected by seasonal changes. ${ }^{55}$

\section{Synergism Testing using the Checkerboard Dilution Method}

Drug synergism is a novel concept and could be beneficial (synergistic or additive interaction) or deleterious (antagonistic or toxic outcome). According to Adwan and Mhanna, combined antibiotic therapy can delay bacterial resistance and may also produce desirable synergistic effects in the treatment of bacterial infection. ${ }^{56}$ Furthermore, Chanda and Rakholiya have pointed out the use of plant extracts and combination therapy as effective approaches in addressing emerging antibiotic resistance. ${ }^{57}$ These synergistic or improved effects can be attributed to the mechanism of action of the plant extract on the resistant organisms for a particular antibiotic. Sato et al. described a mechanism wherein polyphenols, a component of various plant extracts including PA extract, exert its antibacterial action through membrane perturbations. ${ }^{58}$ This perturbation of the cell membrane coupled with the action of $\beta$-lactams on the transpeptidation of the cell membrane could lead to an enhanced antimicrobial effect when used in combination. ${ }^{59}$ It was also shown that some plant-derived compounds can improve the in vitro activity of some peptidoglycan inhibiting antibiotics by directly attacking the same site (i.e. peptidoglycan) in the cell wall. ${ }^{60}$ Furthermore, plant extracts may act on different targets in an organism, thus addition of a plant extract could lead to multi-target mode of action in inhibiting the growth of an organism aside from the mechanism of action of a certain antibiotic.

PA crude extract in half the MIC $(60 \mathrm{mg} / \mathrm{mL})$, the MIC $(130 \mathrm{mg} / \mathrm{mL})$, and twice the MIC $(250 \mathrm{mg} / \mathrm{mL})$ demonstrated indifferent reactions with the MIC of penicillin $(0.06 \mu \mathrm{g} / \mathrm{mL})$. Indifference was also observed in half the MIC of penicillin $(0.03 \mu \mathrm{g} / \mathrm{mL})$ combined with the MIC $(130 \mathrm{mg} / \mathrm{mL})$ and half the MIC $(60 \mathrm{mg} / \mathrm{mL})$ of PA crude extract. This finding suggests that the penicillin and PA extract in these concentrations exhibit their bacterio- 
static effect independently, and have equivalent effects whether used in combination or used alone. The bacterial cell wall inhibitory effect of penicillin does not produce a synergistic interaction with the action of the active components of the PA crude extract in inhibiting the growth of the $S$. pyogenes. However, growth of $S$. pyogenes was observed in the combination of twice the MIC $(0.12 \mu \mathrm{g} /$ $\mathrm{mL}$ ) of penicillin with the different concentrations of $\mathrm{PA}$ crude extract, as well as the half the MIC of penicillin (0.03 $\mu \mathrm{g} / \mathrm{mL})$ combined with twice the MIC $(250 \mathrm{mg} / \mathrm{mL})$ of PA crude extract. This suggests that high concentrations of penicillin reduce the inhibitory effects of PA crude extract against $S$. pyogenes, as well as high concentration of PA crude extract diminish the bacteriostatic effect of half the MIC of penicillin against $S$. pyogenes. Tafesh et al. described this occurrence of growth in the presence of a cell wall inhibitor as a result of interaction between the drug and the various components of the plant extract. ${ }^{61}$ Its occurrence in the combination of various concentrations of PA crude extract with the high concentration of penicillin, and in the high concentration of the PA crude extract with low concentration of penicillin suggests a concentrationdependent effect in the inactivation or inhibition of the mechanism of actions of these antimicrobials in producing bacteriostatic effect. However, PA crude extract did not demonstrate either synergistic or antagonistic reaction with penicillin in any combination when tested for bactericidal effect. The difference in the effects seen in the broth and in the agar plates may be attributed to the fact that killed $S$. pyogenes may also exhibit turbidity in broth since dead cells cannot be distinguished from the living cells. It is also possible that during the time when the MIC is being determined, the organisms are in already in their stationary phase transitioning into their death phase. ${ }^{62}$

Twice the MIC $(60 \mathrm{mg} / \mathrm{mL})$, the MIC $(30 \mathrm{mg} / \mathrm{ml})$, and half the MIC $(15 \mathrm{mg} / \mathrm{mL})$ of PA crude extract exhibited indifferent inhibitory effect on the growth of $C$. albicans when combined with twice the MIC of nystatin $(0.08 \mu \mathrm{g} /$ $\mathrm{mL})$. Furthermore, indifferent inhibitory effect was also observed in the combination of twice the MIC of $(60 \mathrm{mg} /$ $\mathrm{mL})$ PA crude extract with the MIC $(0.04 \mu \mathrm{g} / \mathrm{mL})$ and half the MIC $(0.02 \mu \mathrm{g} / \mathrm{mL})$ of nystatin. This suggests that high concentrations of PA crude extract can inhibit the growth of $C$. albicans independently when combined with any concentration of nystatin that has inhibitory effect. This indicates that the ergosterol antagonistic effect of nystatin in the production of fungi cell wall is independent of, or does not have any interaction with, the ability of the PA crude extract to inhibit the growth of $C$. albicans. However, growth was observed when the MIC $(0.04 \mu \mathrm{g} / \mathrm{mL})$ and half the MIC $(0.02 \mu \mathrm{g} / \mathrm{mL})$ of nystatin were combined with the MIC (30 $\mathrm{mg} / \mathrm{mL})$ and half the MIC $(15 \mathrm{mg} / \mathrm{mL})$ of PA crude extract. This indicates presence of a dose-dependent interaction between PA crude extract and nystatin. ${ }^{63}$ In addition, twice the MIC $(60 \mathrm{mg} / \mathrm{mL})$ of PA extract combined with twice
$(0.08 \mu \mathrm{g} / \mathrm{mL})$ and half $(0.02 \mu \mathrm{g} / \mathrm{mL})$ the MIC of nystatin also exhibited indifference in terms of fungicidal effect.

Lastly, the inhibitory effect of crude PA extract on the growth of $S$. pyogenes and C. albicans indicates that it can be used as an alternative treatment in managing infections caused by these organisms as there is promising results in inhibiting growth of these organisms. This was supported by a study done by Rodvold, which stated that the primary measure of antibiotic activity is the MIC, and the PA crude extract exhibited this concentration at $130 \mathrm{mg} / \mathrm{mL}$ and $30 \mathrm{mg} / \mathrm{mL}$ for $S$. pyogenes and C. albicans, respectively. ${ }^{64}$

\section{CONCLUSION}

Crude leaf extract of Plectranthus amboinicus locally known as oregano, can be used to inhibit the growth of common throat pathogens, namely Streptococcus pyogenes (130 $\mathrm{mg} / \mathrm{mL}$ ) and Candida albicans $(30 \mathrm{mg} / \mathrm{mL})$. As reported in other antimicrobial testing studies, MIC is the primary measure of a drug's antimicrobial property, hence we can conclude that PA extract is effective against $S$. pyogenes and $C$. albicans. Furthermore, synergy testing revealed that combining PA crude extract with either penicillin (against $S$. pyogenes) or nystatin (against C. albicans) resulted to indifference, or just equivalent to the individual inhibitory capacity of each antimicrobial. Thus, crude PA extract is an alternative treatment in managing infections caused $S$. pyogenes and C. albicans even when used alone.

With these results, further studies can be done with the aim of developing drugs that utilize Plectranthus amboinicus extract as antimicrobial agent against $S$. pyogenes and C. albicans.

\section{Statement of Authorship}

The primary author conceptualized the research, and spearheaded the data collection, analysis, and writing of the paper. The co-authors participated in the data collection and analysis. The advisers supervised the conduct of the research. All authors approved the final version of the research paper.

\section{Author Disclosure}

All authors declared no conflicts of interest.

\section{Funding Source}

This research work was self-funded.

\section{REFERENCES}

1. Maramba NPC, Saludez JD, Sia IC, Alegre OY, Solis-De Asis GA, Bagnaes LB et al. Guidebook on the Use of Medicinal Plants. Taguig, Metro Manila: Department of Science and Technology and Philippine Council for Health Research and Development; 1993. p. 64.

2. Agron EB. Oregano tea: A profitable venture for the health conscious Filipinos. Bureau of Agricultural Research, Philippines. 2003. http:// www.bar.gov.ph/ news/oreganotea.asp. Accessed August 11, 2011. 
3. Subhas CM, Harsha R, Dinesha R, Thammanna GSS. Antibacterial activity of Coleus aromaticus leaves. Int J Pharm Sci. 2010; 2 Suppl 1: 63-6.

4. CLSI document M7-A7: Methods for Dilution Antimicrobial Susceptibility Tests for Bacteria that Grow Aerobically; Approved Standard, 7th ed. January 2006.

5. CLSI document M27-A2: Reference Method for Broth Dilution Antifungal Susceptibility Testing of Yeasts; Approved Standard, 2nd ed.

6. Clinical Microbiology Procedures Handbook. http://vanguardia. udea.edu.co/ cursos/Bacteriologia/Hand\%20Book/sections/05.12.pdf. Accessed February 06, 2012.

7. Jung EK. Chemical Composition and Antimicrobial Activity of the Essential Oil of Chrysanthemum indicum Against Oral Bacteria. J Bacteriol Virol. 2009 Jun;39(2):61-69. English. https://doi. org/10.4167/jbv.2009.39.2.61

8. Smith TC. Streptococcus (Group A), 2nd ed. NY: Chelsea House; 2010. ISBN-13: 978-1-4381-3288-4.

9. Kayser FH, Bienz KA, Eckert J, Zinkernagel RM. Medical microbiology. Stuttgart: Georg Thieme Verlag; 2005.

10. Russell W, Herwald H. Concepts in bacterial virulence. Switzerland: Reinhardt Druck, Basel; 2004. ISBN 3-8055-7786-9.

11. Stearns SC, Koella JC. Evolution in health and disease. Oxford, NY: Oxford University Press; 2008. ISBN 978-0-19-920746-6.

12. Pichichero ME. Clinical management of streptococcal pharyngitis. USA: Professional Communications, Inc. ISBN 978-1-932610-154.

13. Gaworzewska E, Colman G. Changes in the pattern of infection caused by Streptococcus pyogenes. Epidemiol Infect. 1988;100(2):257-269.

14. Brandt CM, Spellerberg B, Honscha M, Truong ND, Hoevener B, Lütticken R. Typing of Streptococcus pyogenes Strains Isolated from Throat Infections in the Region of Aachen, Germany. Infection 2001 29, 163-165.

15. Brandt CM,Honscha M, Truong ND, Holland R, Hövener B, Bryskier A, Lütticken R, Reinert RR. Macrolide resistance in Streptococcus pyogenes isolates from throat infections in the region of Aachen, Germany. Microb Drug Resist. 2001 Summer;7(2):165-70.

16. Varaldo PE, Debbia EA, Nicoletti G, Pavesio D, Ripa S, Schito GC, Tempera G. Nationwide survey in Italy of treatment of Streptococcus pyogenes pharyngitis in children: influence of macrolide resistance on clinical and microbiological outcomes. Artemis-Italy Study Group. Clin Infect Dis. 1999 Oct;29(4):869-73.

17. Österlund A,Popa R, Nikkila T, Scheynius A, Engstrand L. Intracellular reservoir of Streptococcus pyogenes in vivo: a possible explanation for recurrent pharyngotonsilitis. Laryngoscope. 1997 May;107(5):640-7.

18. Bisno AL. Acute pharyngitis. N Engl J Med. 2001 Jan 18;344(3): 205-11.

19. Feder HM Jr, Gerber MA, Randolph MF, Stelmach PS, Kaplan EL. Once-daily therapy for streptococcal pharyngitis with amoxicillin. Pediatrics. 1999 Jan;103(1):47-51.

20. Van Asselt GJ, Sloos JH, Mouton RP, Van Boven CP, Van de Klundert JA. Susceptibility of Streptococcus pyogenes to azithromycin, clarithromycin, erythromycin and roxithromycin in vitro. J Med Microbiol. 1995 Nov;43(5):386-91.

21. Herron JM. Roxithromycin in the therapy of Streptococcus pyogenes throat infections. J Antimicrob Chemother. 1987 Nov;20 Suppl B: 139-44. doi: 10.1093/jac/20.suppl_b.139.

22. Ryan KJ, Ray CG, eds. Sherris Medical Microbiology, 4th ed. McGraw Hill; 2004. ISBN 0-8385-8529-9.

23. Longo DL, Fauci AS, Kasper DL, Hauser SL, Jameson J, Loscalzo J. eds. Harrison's Principles of Internal Medicine, 18e. New York, NY: McGraw-Hill; 2012.

24. Alora BD, Manaloto C. Nosocomial Infection: Clinical Features of Two Hundred Forty Three Cases in the Santo Tomas University Hospital. The Philippine Journal of Microbiology and Infectious Diseases. 1983 January to June.

25. Thompson GR 3rd, Patel PK, Kirkpatrick WR, Westbrook SD, Berg D, Erlandsen J, Redding SW, Patterson TF. Oropharyngeal candidiasis in the era of antiretroviral therapy. Oral Surg Oral Med Oral Pathol Oral Radiol Endod. 2010 Apr;109(4):488-95.
26. Villar CC, Dongari-Bagtzoglou A. Immune defence mechanisms and immunoenhancement strategies in oropharyngeal candidiasis. Expert Reviews in Molecular Medicine. 2008;10:e29.

27. Collins CD, Cookinham S, Smith J. Management of oropharyngeal candidiasis with localized oral miconazole therapy: efficacy, safety, and patient acceptability. Patient Prefer Adherence. 2011;5:369-74.

28. de Repentigny L, Lewandowski D, Jolicouer P. Immunopathogenesis of Oropharyngeal Candidiasis in Human Immunodeficiency Virus Infection. Clinical Microbiology Reviews Oct 2004, 17 (4) 729-759.

29. Kusch H, Biswas K, Schwanfelder S, Engelmann S, Rogers PD, Hecker M, Morschhäuser J. A proteomic approach to understanding the development of multidrug-resistant Candida albicans strains. Mol Genet Genomics. 2004 Jun;271(5):554-65.

30. Pillai PG, Suresh P, Aggarwal G, Doshi G, Bhatia V.Pharmacognostical standardization and toxicity profile of the methanolic leaf extract of Plectranthus amboinicus (Lour) spreng. J. Applied Pharma. Sci. 2011;1:75-81.

31. Patel R. Hepatoprotective effects of Plectranthus amboinicus (Lour) Spreng against carbon tetrachloride-induced hepatotoxicity. J Nat Pharm. 2011;2:28-35.

32. Pritima RA, Pandian RS. Antimicrobial activity of Coleus aromaticus (Benth) against microbes of reproductive tract infections among women. Afr. J. Infect. Dis. 2007;1(1):18-24.

33. Upadhaya AP, Somvanshi C. Screening for the antimicrobial potentials of some of the plant extracts and phytochemical on the test organisms. International Research Journal. 2010;1(6):118-9.

34. Chandrappa S, Harsha R, Dinesha R, Gowda T. Antibacterial activity of Coleus aromaticus leaves. Int J Pharmacy Pharm Sci. 2010;2(3): 63-6.

35. Sahgal G, Sreeramanan S, Sasidharan S, Xavier R, Ong MT. Screening selected medicinal plants for antibacterial activity against methicillinresistant Staphylococcus aureus (MRSA). Advances in Natural and Applied Sciences. 2009;3(3):330-8.

36. George L. Bactericidal activity on selected leaf extracts. J. Biosci. Res. 2010;1(3):208-11.

37. S. PT, Saj OP. Phytochemical screening, antimicronial and anthelmintic studies on Coleus aromaticus Benth. International Journal of Pharmaceutical Research and Development. 2011;3(4):93-103.

38. Khare RS, Banerjee S, Kundu K. Coleus aromaticus Benth - A Nutritive Medicinal Plant of Potential Therapeutic Value. International Journal of Pharma and Bio Sciences. 2011;2(3):488-500.

39. Revathi A, Thangabalan B, Vengal Rao P, Vadivel K. Microbiological activity of essential oil extracted from Coleus aromaticus Linn. leaves. Research Journal of Pharmaceutical, Biological and Chemical Sciences. 2011;2(1):12-4.

40. Khare RS, Karmakar S, Banerjee S, Nath G, Kundu S, Kundu K. Uropathogen resistant essential oils of Coleus aromaticus and Ocimum sanctum. International Journal of Pharmaceutical Sciences and Research. 2011;2(8):2168-72.

41. Rout OP, Rout KK, Acharya R, Mishra SK. Preliminary Pharmacognostical and Phytochemical evaluation of Coleus aromaticus Benth. leaf. International Journal of Pharma World Research. 2010;1(4):1-19.

42. Joshi RK, Badakar V, Kholkute SD. Carvacrol Rich Essential Oils of Coleus aromaticus (Benth.) from Western Ghats Region of North West Karnataka, India. Advances in Environment. 2011;5(6):1307-10.

43. Guo N, Liu J, Wu X, Bi X, Meng R, Wang X, Xiang H, Deng X, Yu $\mathrm{L}$. Antifungal activity of thymol against clinical isolates of fluconazolesensitive and -resistant Candida albicans. J Med Microbiol. 2009 Aug;58(Pt 8):1074-1079.

44. Qiu J, Feng H, Lu J, Xiang H, Wang D, Dong J, Wang J, Wang X, Liu J, Deng X. Eugenol reduces the expression of virulence-related exoproteins in Staphylococcus aureus. Appl Environ Microbiol. 2010 Sep;76(17):5846-51.

45. Derwich E, Benziane Z, Manar, A. GC/MS Analysis and In vitro Antibacterial Activity of the Essential Oil Isolated from Leaf of Pistacialentiscus Growing in Morocoo. World Applied Sciences Journal. 2010;8(10):1267-76.

46. Cowan MM. Plant products as antimicrobial agents. Clin Microbiol Rev. 1999;12:564-82. 
47. Carson CF, Mee BJ, Riley TV. Mechanism of action of Melaleucaalternifolia (tea tree) oil on Staphylococcus aureus determined by time-kill, lysis, leakage, and salt tolerance assays and electron microscopy. Antimicrob Agents Chemother. 2002;46: 1914-20.

48. Chandrappa S, Harsha R, Dinesha R, Gowda T. Antibacterial activity of Coleus aromaticus leaves. Int J Pharmacy Pharm Sci. 2010;2(3): 63-6.

49. Sahgal G, Sreeramanan S, Sasidharan S, Xavier R, Ong MT. Sreening selected medicinal plants for antibacterial activity against methicillinresistant Staphylococcus aureus(MRSA). Advances in Natural and Applied Sciences. 2009;3(3):330-8.

50. S. PT, Saj OP. Phytochemical screening, antimicronial and anthelmintic studies on Coleus aromaticus Benth. International Journal of Pharmaceutical Research and Development. 2011;3(4):93-103.

51. Khare RS, Banerjee S, Kundu K. Coleus aromaticus Benth - A Nutritive Medicinal Plant of Potential Therapeutic Value. International Journal of Pharma and Bio Sciences. 2011;2(3):488-500.

52. Revathi A, Thangabalan B, Vengal Rao P, Vadivel K. Microbiological activity of essential oil extracted from Coleus aromaticusLinn. leaves. Research Journal of Pharmaceutical, Biological and Chemical Sciences. 2011;2(1):12-4.

53. Pritima RA, Pandian RS. Antimicrobial activity of Coleus aromaticus (Benth) against microbes of reproductive tract infections among women. Afr J Infect Dis. 2007;1(1):18-24.

54. Tschesche R. Advances in the chemistry of antibiotics substances from higher plants: Pharmacognosy and phyto-chemistry. In: Wagner $\mathrm{H}$, Horharmmer L, eds. Proceeding of the 1st International Congress, Murich, 1970. Springer-Verlag, Berlin Heidelberg, New York; 1971. pp. 274-89.

55. Johnson CB, Kazantzis A, Skoula M, Mitteregger U, Novak J. Seasonal, populational and ontogenic variation in the volatile oil content and composition of individuals of Origanumvulgare subsp. Hirtum, assessed by GC headspace analysis and by SPME sampling of individual oil glands. (Abstract) Phytochem Anal. 2004;15: 286-92. doi: 10.1002/pca.780.
56. Adwan A, Mhanna M. Synergistic Effects of Plant Extracts and Antibiotics on Staphylococcus aureus Strains Isolated from Clinical Specimens. Middle East Journal of Scientific Research. 2008;3(3): 134-9.

57. Chanda S, Rakholiya K. Combination therapy: Synergism between natural plant extracts and antibiotics against infectious diseases. In: Méndez-Vilas A, ed. Science against microbial pathogens: communicating current research and technological advances. India: Formatex; 2011.

58. Sato M, Tanaka H, Yamaguchi R, Kato K, Etoh H. Synergistic effects of mupirocin and an isoflavanone isolated from Erythrina variegata on growth and recovery of methicillin-resistant Staphylococcus aureus. Int J Antimicrob Agents. 2004;24:43-8.

59. Esimone CO, Iroha IR, Ibezim EC, Okeh CO, Okpana EM. In vitro evaluation of the interaction between tea extracts and penicillin $G$ against Staphylococcus aureus. Afr J Biotechnol. 2006;5:1082-6.

60. Zhao WH, Hu ZQ, Okubo S, Hara Y, Shimamura T. Mechanism of synergy between Epigallochatechingallate and $\beta$-Lactams against methicillin resistant Staphylococcus aureus. Antimicrob Agents Chemother. 2001;45:1737-42.

61. Tafesh A, Najami N, Jadoun J, Halahlih F, Riepl H, Azaizeh H. Synergistic Antibacterial Effects of Polyphenolic Compounds from Olive Mill Wastewater. Evidence-Based Complementary and Alternative Medicine. 2001:11.

62. Todar, K. Todar's Online Textbook of Bacteriology. Department of Bacteriology. University of Wisconsin-Madison. [Internet] [cited 2012 March 18]. Available from: http://textbookofbacteriology.net/ themicrobialworld/growth.html.

63. Archana S, Abraham J. Comparative Analysis of antimicrobial activity of leaf extracts from fresh green tea, commercial green tea and black tea on pathogens. Journal of Applied Pharmaceutical Science. 2011;1(08):149-52.

64. Rodvold KA. Pharmacodynamics of antiinfective therapy: taking what we know to the patient's bedside. Pharmacotherapy. 2001 November;21(11 Pt 2):319S-30S. 